
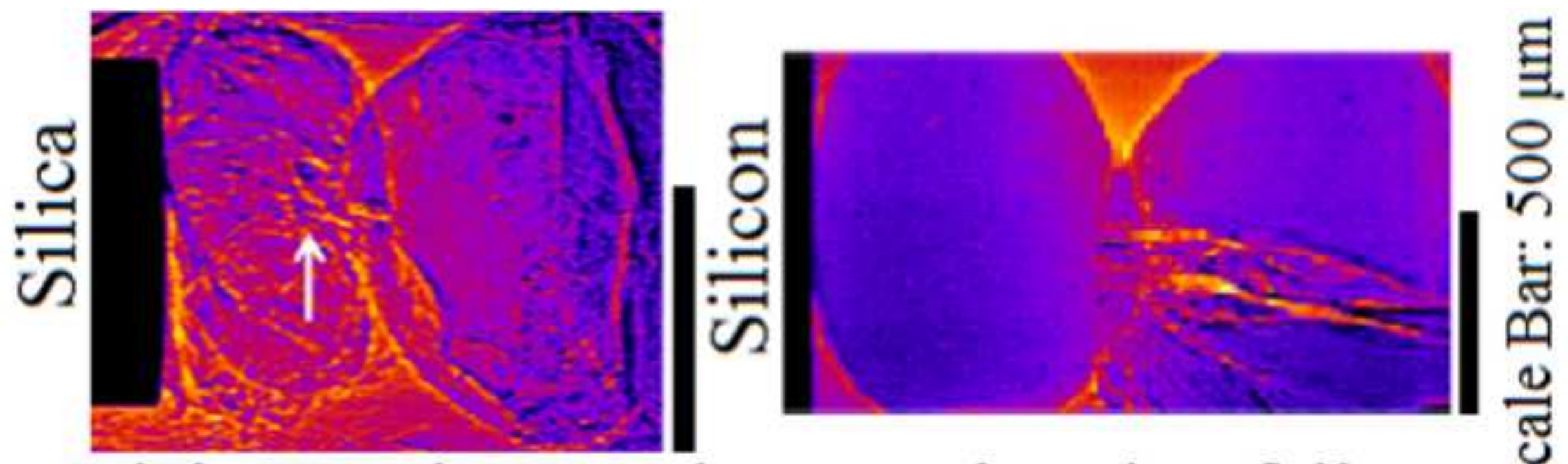

High speed X-ray images showing failure थ mechanism under dynamic compression 


\title{
New pulverization parameter derived from indentation and dynamic compression of brittle microspheres
}

\author{
Mohamad B. Zbib ${ }^{1}$, Niranjan D. Parab ${ }^{2}$, Weinong W. Chen ${ }^{1,2}$, David F. Bahr ${ }^{1 *}$ \\ ${ }^{1}$ School of Materials Engineering, Purdue University. West Lafayette, IN 47907 \\ ${ }^{2}$ School of Aeronautics and Astronautics, Purdue University, West Lafayette, IN, 47907
}

\begin{abstract}
Particulates may experience dynamic compression loading during materials handling and processing, which in turn can lead to fracture of the particles. In this study, the dynamic fracture behavior of microspherical particles of soda lime glass (SLG), polycrystalline silica, polycrystalline silicon, barium titanate glass (BTG) and yttrium-stabilized zirconia (YSZ) was characterized with high speed, in situ X-ray phase-contrast imaging to examine the failure mechanisms in situ for spheroidal particles with diameters (d) from 600 to $2000 \mu \mathrm{m}$ under dynamic compression. Nanoindentation was used to measure the hardness $(H)$ and elastic modulus $(E)$, and microindentation was used to measure the fracture toughness $(T)$ of the materials. Based on the experimental results, a new pulverization parameter was proposed to predict the failure mechanism of the materials given by: $P=H d / T E^{5 / 3}$. The results showed that high $P$ values are associated with comminution failure, low $P$ values are associated with single cracking failure, and intermediate $P$ values reflect failure modes in between these two extremes.
\end{abstract}

Keywords: pulverization parameter; particle fracture; high strain rate, high speed X-ray phase contrast imaging. 
* Corresponding author:

David F. Bahr

School of Materials Engineering, Purdue University West Lafayette, IN, 47907-2045, USA

dfbahr@purdue.edu

tel: $765-494-4100$ 


\section{Introduction}

Particles or granular solids of brittle materials are subjected to self-impact loading during materials processing, transportation, drilling, blasting, and rapid penetration loading such as ballistic impact. The resulting dynamic compressive loading can lead to a wide range of deformation and fracture behaviors in the particles. The integrity of the granular solid after compression plays a significant role in both the subsequent processing and the energy absorption capabilities of the material. There are established methods in the literature to analyze the fracture energy distribution of particles using quasi-static single particle tests (crushing tests) and studying the breakage of hard particles under controlled loading conditions [1]. Single particle testing is not restricted to inorganic solids; testing of crystalline organic substances to study the milling behavior has compared particle fracture to localized indentation fracture techniques. This has shown that the absorption energy and the resistance to fracture of a particulate can be related to a brittleness index (often defined as the ratio of hardness to fracture toughness) [2].

The behavior of spherical particles under impact loading has been studied using various experimental methods. In several studies, a spherical particle was impacted against a rigid target at a high velocity [3-9]. Andrews and Kim observed that particles fracture upon impact only if the impact velocity is higher than a certain threshold velocity [6]. Salman et al. reported the cracking behavior for various brittle particles, including PMMA and soda-lime glass, using postmortem observation of the fragments collected after impact [9]. In-situ observation of failure behavior has been reported for glass spheres, where they were observed to undergo explosive fragmentation upon impact on a hard anvil [6,7]. Several studies have utilized particle impact experiments to obtain the probability of particle failure in an aggregate particulate solid [10-12]. Dynamic diametral compression using a drop tower testing machine has also been used to apply 
impact loading $[13,14]$. Chau et al. observed plaster particles failing in two hemispheres or three 'orange slices' under dynamic diametral compression [13]. In the same paper, Chau et al. reported that the failure modes in the particle under dynamic compression were identical to those observed under static compression [13].

The aforementioned single particle experiments cannot account for the effects of particleparticle contacts which are prevalent in granular solids. Also, it has been impossible to observe the in situ failure mechanisms for the opaque particles. However, a high speed X-ray phase contrast imaging (PCI) technique synchronized with Kolsky bar loading mechanism was recently developed to observe the failure modes in two contacting brittle particles under dynamic compression $[15,16]$. In previous studies, silica sand particles were observed to fracture exclusively in the pulverization failure mode when dynamically compressed [15].

While identifying failure modes using both in situ and post-test characterization is beneficial, the ability to predict failure modes provides guidance for designing both energy absorbing systems as well as predicting morphological changes during powder processing. Ghadiri and Zhang established an experimental and theoretical model of impact attrition of particulate solids for semi-brittle failure [17,18]. They identified a dimensionless attrition propensity parameter that is related to impact conditions (impact velocity) and material properties (particle density, particles size, hardness, and fracture toughness) [17, 18]. Zbib and Bahr recently identified a similar dimensionless attrition propensity parameter for spherical granular polycrystalline silicon which is related to the shape (and therefore stresses at a fixed loading condition), hardness, and elastic modulus of the silicon [19], where lower toughness or larger diameter particles exhibited a higher attrition parameter. However, these attrition parameters only discuss the likelihood of particle size reduction through fracture and do not 
address the particle failure morphology explicitly. Another motivation for studying the fracture behavior of brittle microspheres such as silica and silicon is related to safety and health issues. Studies showed that the operators of sand blasters and stone cutting systems can be subjected to fine silica particulates which can lead to silicosis and lung cancer, both deadly lung diseases $[20,21]$. If the fracture behavior of particles during impact loading and materials processing was better understood, predictions of the dust generated during these processes might be used to limit worker exposure to harmful particulate matter.

In this paper the fracture behavior of micro-spherical particles made up of polycrystalline silica, soda lime glass (SLG), polycrystalline silicon, barium titanate glass (BTG) and yttriumstabilized zirconia (YSZ) under dynamic compression is discussed. Nanoindentation and microindentation were used to study the quasi-static mechanical properties, while the failure mechanisms under dynamic compression were investigated using high speed X-ray PCI. Using these complementary techniques a new pulverization model is proposed to better describe the fracture behavior of granular solids under self-impact loading.

\section{Materials and methods}

Nominally spherical particles composed of five different brittle materials were chosen for this study. Materials were selected to provide a range of materials properties as well as variations in particle size. Material, size and the vendor for each type of particle are summarized

in Table 1. For silicon, BTG, YSZ and silica, both contacting particles were selected from a single monodisperse particle size distribution. For SLG, particles were selected from three different monodisperse particle size distributions. Both contacting particles for a given experiment were chosen from the same distribution. Samples were imaged using scanning 
electron microscopy to verify they were primarily spherical, with simple aspect ratios of the plan view microscopy used to determine the aspect ratio of several representative particles.

Table 1. Material properties, particle size and vendor for each type of particle

\begin{tabular}{|l|l|l|l|l|}
\hline Material & $\begin{array}{l}\text { Particle size } \\
\text { (diameter) } \\
\text { ranges }(\boldsymbol{\mu m})\end{array}$ & Aspect ratio & $\begin{array}{l}\text { Number of impact } \\
\text { compression } \\
\text { experiments }\end{array}$ & Vendor \\
\hline $\begin{array}{l}\text { Polycrystalline } \\
\text { silicon }\end{array}$ & $800-1200$ & $1.02-1.21$ & 27 & $\begin{array}{l}\text { REC Silicon } \\
\text { (Moses Lake, } \\
\text { WA) }\end{array}$ \\
\hline $\begin{array}{l}\text { Soda-lime glass } \\
\text { (SLG) }\end{array}$ & $680-2000$ & $1.00-1.02$ & 23 & $\begin{array}{l}\text { Cospheric LLC } \\
\text { (Santa Barbra, } \\
\text { CA) }\end{array}$ \\
\hline $\begin{array}{l}\text { Barium titanate } \\
\text { glass (BTG) }\end{array}$ & $850-1000$ & $1.02-1.18$ & 5 & $\begin{array}{l}\text { Cospheric LLC } \\
\text { (Santa Barbra, } \\
\text { CA) }\end{array}$ \\
\hline $\begin{array}{l}\text { Yttrium } \\
\text { stabilized } \\
\text { Zirconia (YSZ) }\end{array}$ & $780-850$ & $1.01-1.05$ & 5 & $\begin{array}{l}\text { Cospheric LLC } \\
\text { (Santa Barbra, } \\
\text { CA) }\end{array}$ \\
\hline $\begin{array}{l}\text { Polycrystalline } \\
\text { silica }\end{array}$ & $650-770$ & $1.03-1.18$ & 6 & $\begin{array}{l}\text { U. S. Silica } \\
\text { (Ottawa, IL) }\end{array}$ \\
\hline
\end{tabular}

The specimens used for measuring the mechanical properties of individual spherical particles were prepared using conventional grinding and polishing methods. The granular particles were mounted in epoxy and ground with 350 to 1200 grit silicon carbide abrasive paper, and then polished using diamond paste from 6 to $0.5 \mu \mathrm{m}$. These sample preparations were done only for Vickers indentation and nanoindentation tests.

The high speed impact experiments were performed on specimens with no prior sample preparation. In all cases the peak to valley roughness of the surface of the spheroidal particles was much less than $(<5 \%)$ that of the radius, and while some particles are not perfectly spherical, for the purposes of this work a first order spherical radius that averages the diameters from the particle size distributions will be used to define particle size. 
The hardness $(H)$ and elastic moduli $(E)$ of the five materials were determined using a Hysitron Triboindenter TI 950 to perform nanoindentation experiments in which the applied load, $F$, and indenter displacement are recorded throughout the test. Quasi-static testing was performed with maximum applied loads between 5000 and $8500 \mu \mathrm{N}$. All measurements (about 15 tests of each material) were done at areas smaller than any pore or defect spacing to avoid morphological influence on the measured materials properties. The Oliver and Pharr method was used to calculate the hardness and the modulus, where the contact area at the peak load and the slope during unloading were taken into consideration [22]. The elastic modulus was calculated using:

$\frac{1}{E_{R}}=\frac{1-v_{i}^{2}}{E_{i}}+\frac{1-v_{S}^{2}}{E_{S}}$

where $E_{R}$ is the reduced modulus determined from the Oliver and Pharr analysis of the unloading slope, $E_{i}$ is the modulus of the diamond indenter tip (1249 GPa), $E_{s}$ is the elastic modulus of the sample, $v_{i}$ and $v_{s}$ are the Poisson's ratio of the diamond indenter tip (0.07) and the sample respectively. The hardness $(H)$ is the ratio of peak indentation load $\left(F_{\max }\right)$ and the known projected area function at maximum load $(A)$ which can be related to the indenter displacement during the nanoindentation test. The hardness was calculated using

$H=\frac{F_{\max }}{A}$

The quasi-static toughness was determined using a Vickers microhardness test, where loads between 0.49 and $4.9 \mathrm{~N}$ were applied to the samples, and an optical microscope was used to measure the crack sizes induced from the indentation experiment [23]. About 30 tests were performed on each material. The fracture toughness $(T)$ of each material was determined using Vickers indentation induced fracture [23] by 
$T=\frac{\chi_{r} F}{c^{3 / 2}}$

where $c$ is the average crack radius, $F$ is the applied load using a Vickers microindenter, and $\chi_{r}$ is a constant that depends on the specific material system

$\chi_{r}=\xi \sqrt{\frac{E}{H}}$

where $E$ and $H$ are the measured elastic modulus and hardness respectively, and $\xi$ is an indenter invariant constant, which is equal to 0.016 for Vickers tip experiments [23].

The failure mechanisms of the particles under dynamic compression were investigated using a combination of a modified Kolsky bar setup and high speed synchrotron X-ray PCI at Advanced Photon Source (APS) beam line 32-ID-B at Argonne National Laboratory, Argonne, IL. This experimental method has been used to study the failure mechanisms in various materials including bone-tissue interfaces, polymer fibers, concrete and rocks, and glass plates [15,16, 24]. The schematic of the experimental setup is presented in Figure 1.

The Kolsky bar experiments are commonly used to characterize material properties at strain rates on the order of $10^{2}-10^{5} \mathrm{~s}^{-1}[25,26]$. In this study, a modified Kolsky bar technique was used to impose controlled dynamic compression on two contacting particles. The transmission bar in the conventional Kolsky bar apparatus was replaced with a heavy aluminum backstop due to space constraints in the APS X-ray hutch. A high intensity polychromatic X-ray beam was passed through the particles as they were compressed. After passing through the particles, the Xray signal was converted to visible light using a scintillator (single crystal $\mathrm{Lu}_{3} \mathrm{Al}_{5} \mathrm{O}_{12}: \mathrm{Ce}$ ). The visible light images on the scintillator were relayed to a high speed camera using a $45^{\circ}$ mirror, a microscope objective, and a tube lens. Photron Fastcam SA1.1 high speed digital camera containing a 12-bit CMOS sensor was used to capture images at various frame rates and frame 
sizes. One of the limitations of the camera was that the frame size reduced as the frame rate was increased.

Two spherical particles were constrained in a custom made aluminum sample holder with the compression loading imposed on the particles using a flat faced steel gage pin. To prevent the interaction of the particles with holder wall, the aluminum holder was machined with a slightly larger inner diameter than the nominal diameter of the particles. The experimental sequence started with a manual start signal that launched the striker bar towards the incident bar. The impact of the striker with the incident bar generated a compressive stress wave in the incident bar. The compressive wave was sensed by the strain gauges on the incident bar that subsequently triggered the camera. The stress wave continued to propagate to the end of the incident bar where it pushed the steel pin onto two contacting particles at a constant speed of $4.9-5.1 \mathrm{~ms}^{-1}$. The high intensity $\mathrm{x}$-ray beam passed through the particles as they were being compressed. Subsequently, the deformation and damage of the particles was recorded by the scintillatorcamera system. For all particles, at least 5 experiments were conducted to ensure repeatability. Numbers of experiments for each particle type are presented in Table 1.

\section{Results and Discussion}

\subsection{Particle Shapes}

The aspect ratio of the particles was measured to better identify their shapes. This ratio was identified as the ratio of the largest projected diameter to the smallest projected diameter of the particle that could be imaged using scanning electron microscopy of at least 5 representative particles. SLG and YSZ have aspect ratios that range between 1.00 and 1.05; they are effectively spherical. However, the aspect ratios of silicon \& silica can reach up to 1.21 , showing a larger 
deviation which may be present in the projected x-ray imaging used to examine in situ particle fracture. The aspect ratios of BTG range between 1.02 and 1.18. The ranges of aspect ratios measurements of each material are listed in Table 1. The roughness of all particles was ignored in the current study as in all cases it is $\sim 5 \%$ of less of the radius or the nominal diameter of the particle.

\subsection{Mechanical Properties}

Both hardness and elastic modulus of each material did not vary significantly within a batch; the values are listed in Table 2. We have chosen to present the measure of material toughness as $T$, rather than reporting a mode I fracture toughness $\left(K_{I C}\right)$ because well-defined pre-cracks and pure mode I opening are not present in the indentation fracture method. For further details, Morris and Cook describe how $T$ is an appropriate surrogate for using indentation induced fracture in place of a more well defined stress state during pure mode I or II toughness testing [23]. The average crack size vs. applied load was plotted as shown in Figure 2, where equation 3 was used to fit the data for each material to determine $T$. The deviations at low loads are likely due to the difficult evaluation of the crack sizes at small loads, and the inhomogeneity of the product. One of the materials, polycrystalline silicon, does exhibit approximately $4 \%$ porosity, however prior studies have shown that the pores present in this material did not show any significant effect on the crack morphology nor the measured toughness [19]. The measured toughnesses of all the materials are listed in Table 2.

\subsection{Failure modes}

The high speed X-ray PCI technique was used to identify the failure modes in different particles. The scintillator-high speed camera setup captured the images in 16-bit greyscale 
format. The raw images were adjusted for the contrast and brightness such that cracks can be easily identified using ImageJ software [27]. Following contrast and brightness adjustment, images were colorized using a native colorization scheme in the ImageJ software package (Look up table: Fire) to make the failure process easier to visualize. Figures 3 to 7 show the failure process in various particles under dynamic compression. The glass particles and silica sand particles showed what is more commonly observed in comminution failure mode, with a significant decrease in particle size after impact. Polycrystalline silicon and barium titanate glass particles showed major cracking between contacts prior to failure, with a particle size reduction after impact to approximately $10 \%$ of the initial particle size. YSZ particles displayed a single crack in one of the particles which separated the particle into two parts, effectively only reducing the particle size by $50 \%$.

Figure 3 shows the failure modes for the soda lime glass particles. Initially, two particles were touching and no compression was applied. As the pin compressed the particles, conical cracks initiated from the contact (Figure 3,t $t=22.1 \mu \mathrm{s}$ ). As the particles were compressed further, one of the particles pulverized violently (Figure 3, $t=66.3 \mu \mathrm{s}$ ). Silica sand particles displayed similar behavior (Figure 4). Interfacial cracks initiated at the contact when the particles were compressed (Figure $4, t=37 \mu \mathrm{s}$ ). The cracked particle subsequently pulverized (i.e. resulting powder size less than $1 \%$ of the initial radius, more similar to what might be expected through significant comminution during particle size reduction processing) when compressed further (Figure 4, $t=74 \mu \mathrm{s}$ ).

Both polycrystalline silicon and BTG particles showed a markedly different failure behavior. The failure process for silicon particles is presented in Figure 5, we will refer to this mode as "major cracking". When the particles were compressed, a finite number of major cracks 
formed in one of the particles (Figure $5, t \approx 18.5 \mu \mathrm{s}$ ). On further compression, the cracked particle fractured into several large fragments and a large number of very small fragments (Figure $5, t \approx 37 \mu \mathrm{s}$ ). The second particle remained intact till the cracked particle fractured completely. BTG particles also showed major cracking failure mode under dynamic compression (Figure 6). In BTG particle compression experiments, the second particle also showed major cracking after sufficient compressive loading had been applied (Figure 6, $t \approx 100 \mu \mathrm{s}$ ).

YSZ particles displayed a remarkably different behavior than the other particles examined in this study (Figure 7). Upon dynamic compression a single crack developed between the contacts (meridonial crack) in one of the particles (Figure $7, t \approx 56 \mu \mathrm{s}$ ). This crack fractured the particle into two parts when the particles were compressed further (Figure $7, t \approx 74 \mu$ s). After breaking, one of the parts of the fractured particle was compressed further between the intact particle and the compressing pin.

\subsection{Pulverization parameter}

As described in the previous section, different particles display widely different failure mechanisms under similar compressive loading. Here we propose an analytical approach to express the relationship between the properties measured using quasi-static indentation techniques (Hardness, modulus, and toughness) and the dynamic compression experiments (failure mechanism). This approach is similar to the brittleness index $\left(B_{i}\right)$ [2] and to Ghadiri \& Zhang's dimensionless attrition parameter $(\eta)[17,18]$, where different parameters were identified, using their terminology, respectively as:

$$
\begin{aligned}
& B_{i}=\frac{H}{T} \\
& \eta=\frac{\rho v^{2} l H}{T^{2}}
\end{aligned}
$$


where $T$ is the fracture toughness, $H$ is the hardness, $l$ is a characteristic particle size (for our calculations, $l$ is equal to the average diameter $d$ of the particle), $v$ is the impact velocity ( $5 \mathrm{~m} / \mathrm{s}$ for all tests taken from the current X-ray experiments), and $\rho$ is the particle density.

Although these parameters can accurately predict the propensity for particle failure in particulate materials, they are unable to predict the failure modes observed in this study. The brittleness index and Ghadiri and Zhang's dimensionless attrition parameter $(\eta)$ for the particles used in this study are plotted in Figure 8(b). For these parameters to describe the morphological failure process, it is expected that the parameter should show a clear trend as the severity of cracking damage increases in the particle. Hence, if these parameters were sufficient to describe the failure mode, the parameter should show either uniformly increasing or decreasing trend as the material is changed from SLG to silica to silicon to BTG and finally to YSZ. However, the two parameters defined in the literature are almost equal for SLG and BTG and show a maximum for silicon.

To properly explain the observed trend in comminution behavior across material type, a modified attrition propensity parameter, defined here as the pulverization parameter $(P)$ has been identified which depends on the diameter $(d)$, the hardness $(H)$, elastic modulus $(E)$, and toughness $(T)$ of the spherical particle. The motivation for the parameter is as follows. We begin with the assumption that $P$ should be larger as the propensity to pulverize and form smaller final particle sizes during particle fracture increases. If $H$ is higher, then dislocations are more difficult to move in the structure of the material (or other plastic processes such as twinning or densification are similarly more difficult to occur) and less energy is expended in plastic deformation, so $P$ increases and therefore:

$\mathrm{P} \propto H$ 
Similarly, when $T$ is higher, the particles exhibit less fracture, so it is less likely for the particles to pulverize and therefore:

$$
\mathrm{P} \propto \frac{1}{T}
$$

The strain energy that is added to the particle is proportional to $E$ at a given strain. The strain energy is inversely related to comminution of the material and therefore:

$\mathrm{P} \propto \frac{1}{E}$

The relative displacement between the centers of two particles is related to the contact area and the particle radius using standard Hertzian contact mechanics, where the contact area is inversely proportional to the maximum pressure [28]. When the contact area increases, comminution decreases since the maximum pressure also decreases. However, the contact area is proportional to the displacement which is proportional to $\left(1 / \mathrm{E}^{2 / 3}\right)$ based on the Hertzian equation for the elastic contact of spheres [28], hence the modulus should be related to $P$ in an additional term:

$\mathrm{P} \propto \frac{1}{E^{2 / 3}}$

Finally, we must consider the method by which the test was run. As this testing geometry is effectively a displacement imposed test with fixed grips (the test is not load controlled; in the impact conditions here, we assume there is overly sufficient loading capability present and the particles deform in a fixed grips condition to conform to the motion of the striker plate) the maximum pressure within a particle should scale with the particle diameter.

$\mathrm{P} \propto d$

The diameter of each tested particle was measured and $d$ is the calculated arithmetic mean diameter of all the tested particles for each material. The average diameter values are listed in Table 2. 
The mean pressure $\left(p_{0}\right)$ was calculated based on Hertz theory of elastic contact [28], which is related to the contact radius $(a)$ that was measured from the high speed X-ray images when the two particles are in contact; we choose here the frame which exhibits the largest contact area between the particles prior to fracture; obviously this is an underestimate of the maximum mean pressure as the contact radius between the particles may continue to increase in the time interval between frames. However, to first order this should provide a reasonable estimate of pressure prior to fracture and a starting point for future method development. The mean pressure is

$p_{0}=\frac{4 a E}{\pi d}$

Combining equations (7) to (11), the pulverization parameter is defined as:

$\mathrm{P}=\frac{H d}{T E^{5 / 3}}$

The results of calculation by equations $5,6,12$, and 13 for each material are listed in Table 2 .

Table 2. Mechanical properties and failure (attrition) parameters for tested particulate materials ${ }^{\mathrm{a}}$. Density values were provided by the vendor for each material.

\begin{tabular}{|c|c|c|c|c|c|}
\hline & SLG & Silica & Silicon & BTG & YSZ \\
\hline $\begin{array}{c}\text { Hardness, } H \\
\text { (GPa) }\end{array}$ & $6.5 \pm 0.3$ & $13.8 \pm 0.6$ & $9.7 \pm 0.4$ & $5.3 \pm 0.3$ & $16.0 \pm 0.7$ \\
\hline $\begin{array}{c}\text { Elastic Modulus, } E \\
(\mathrm{GPa})\end{array}$ & $83 \pm 6$ & $111 \pm 5$ & $164 \pm 4$ & $77 \pm 5$ & $255 \pm 7$ \\
\hline $\begin{array}{c}\text { Toughness, } T \\
\left(\text { MPa.m }^{0.5}\right) \\
\end{array}$ & $1.28 \pm 0.08$ & $1.07 \pm 0.04$ & $0.60 \pm 0.05$ & $1.10 \pm 0.07$ & $5.69 \pm 0.16$ \\
\hline $\begin{array}{l}\text { Mean pressure at } \\
\text { fracture, } p_{0}(\mathrm{GPa}) \\
(\text { Eq. 12) }\end{array}$ & 19 & 25 & 78 & 13 & 104 \\
\hline Density, $\rho\left(\mathrm{kg} / \mathrm{m}^{3}\right)$ & 2500 & 2650 & 2330 & 4140 & 6020 \\
\hline $\begin{array}{c}\text { Average diameter, } d \\
(\mu \mathrm{m})\end{array}$ & 1285 & 691 & 966 & 923 & 822 \\
\hline $\begin{array}{c}\text { Brittleness index, } B_{i} \\
\left(\mathrm{~m}^{-.05}\right)(\text { Eq. 5) }[2]\end{array}$ & $5.1 \times 10^{3}$ & $1.3 \times 10^{4}$ & $1.6 \times 10^{4}$ & $4.8 \times 10^{3}$ & $2.8 \times 10^{3}$ \\
\hline Ghadiri \& Zhang & 0.32 & 0.55 & 1.52 & 0.42 & 0.061 \\
\hline
\end{tabular}




\begin{tabular}{|c|c|c|c|c|c|}
\hline $\begin{array}{c}\text { parameter, } \boldsymbol{\eta} \text { (Eq. 6) } \\
{[\mathbf{1 7 , 1 8}]}\end{array}$ & & & & \\
\hline $\begin{array}{c}\text { Pulverization } \\
\text { Parameter, } \boldsymbol{P} \\
(\mathbf{E q . ~ 1 3 )}\end{array}$ & $\begin{array}{c}4.1 \times 10^{-3} \pm \\
1.6 \times 10^{-4}\end{array}$ & $\begin{array}{c}3.5 \times 10^{-3} \pm \\
2.1 \times 10^{-4}\end{array}$ & $\begin{array}{c}3.2 \times 10^{-3} \pm \\
4.1 \times 10^{-4}\end{array}$ & $\begin{array}{c}3.2 \times 10^{-3} \pm \\
2.9 \times 10^{-4}\end{array}$ & $\begin{array}{c}2.3 \times 10^{-4} \pm \\
6.8 \times 10^{-6}\end{array}$ \\
$\left(\mathbf{m}^{\mathbf{0 . 5}} / \mathbf{G P a} \mathbf{5 / 3}\right)$ & & & & \\
\hline Failure mode & Comminution & Comminution & Major cracks & Major cracks & Single crack \\
\hline
\end{tabular}

${ }^{\mathrm{a}}$ Between 15 and 30 indentation tests were performed for each material to calculate the average values and standard deviations of $H, E$, and $T$.

The new pulverization model gives a better understanding for the fracture behavior of different materials under compression tests. SLG that has the highest pulverization parameter $P$ value showed comminution failure in the particles (i.e. a particle size reduction on the order of more than $95 \%$ from the initial spherical particle radius); YSZ that has the smallest $P$ value showed single cracking (i.e. the particle splits into two particles); medium $P$ values was associated with major cracking failure as seen in silicon and BTG (i.e. a particle size reduction between 50 and $90 \%$ from the initial radius). Silica has $P$ value that is not as high as SLG, but a little higher than the $P$ values of silicon and BTG, and it showed comminution failure. All $P$ values are shown in Fig. 8a. The difference in the $P$ value between SLG and silica particles in mostly to the range of the diameters of the tested particles because this model is sensitive to the particle size.

Fig. $8 \mathrm{~b}$ shows how other attrition parameters do not follow similar trend to the failure mechanisms under dynamic compression; similarly the mean pressure at failure initiation shown in Table 2 is not sufficient to describe the trend. Based on the identified failure mechanisms of the pulverization parameter, it is observed that different shapes exist in each category; for instance, SLG particles that are spherical have similar failure mechanism to silica particles that are more ellipsoidal, suggesting that this newly proposed parameter $P$ is relatively robust in 
describing the reduction in particle size during self particle impact and, to first order, not particularly sensitive to the spheriodicity of the sample.

The importance of this new pulverization model is to address the influence of strain energy added to the system as particles compress, along with the hardness and toughness of the material on the overall particle failure morphology. The pulverization parameter values that have been shown in this study do not match with the calculations based on the other published parameters nor the mean pressure at failure; therefore, it would not be possible to predict the observed varied failure mechanisms based on the previously published parameters. Combining indentation techniques and dynamic compression experiments to develop this new model is a valuable way to classify different materials for design and application purposes; this is a phenomenological model that can be exercised for other brittle spherical particles systems. The transition from major cracking failure to single cracking failure is clearly observed in the $P$ values. However, the transition between comminution failure to major cracking failure is not abrupt. Future work should include more predictive model that can identify more clearly specific thresholds that is less sensitive to particle sizes.

\section{Conclusions}

In this study, a new attrition model was proposed to better describe the morphological fracture mechanisms and failure behavior of brittle microspheres under high strain rate dynamic loading. This phenomenological model is represented by a pulverization parameter $(P)$ that is related to the hardness $(H)$, elastic modulus $(E)$, fracture toughness $(T)$, and the size $(d)$ of the particles assuming fixed grips loading conditions with excessive load applied. It is identified as

$\mathrm{P}=\frac{H d}{T E^{5 / 3}}$ 
Three different failure mechanisms have been identified based on the relationship between the dynamic compression experiments and the indentation measurements. High $P$ values are associated with comminution failure, low $P$ values are associated with single cracking failure, and medium $P$ values span a range of failure modes between comminution and single cracking failure. Further investigation should account for a more predictive model regarding the intersection between both the comminution and major cracking failure mechanisms.

\section{Acknowledgments}

We appreciate professional help from A. Deriy with certain technical and safety aspects of our experiments at the APS. Use of the Advanced Photon Source, an Office of Science User Facility operated for the U.S. Department of Energy (DOE) Office of Science by Argonne National Laboratory, was supported by the U.S. DOE under Contract no. DE-AC02-06CH11357. This research was partially supported by the ONR Grant N00014-14-1-0628 (Program manager: Dr. David Shifler).

\section{References}

[1] C. R. Bemrose and J. Bridgwater, "A review of attrition and attrition test methods," Powder Technol., vol. 49, pp. 97-126, 1987.

[2] B. R. Lawn and D. B. Marshall, "Hardness, toughness, and brittleness: an indentation analysis," J. Am. Ceram. Soc., vol. 62, pp. 347-350, 1979.

[3] P. H. Shipway and I. M. Hutchings, "Attrition of brittle spheres by fracture under compression and impact loading," Powder Technol., vol. 76, pp. 23-30, 1993.

[4] P. H. Shipway and I. M. Hutchings, "Fracture of brittle spheres under compression and impact loading II: Results for lead-glass and sapphire spheres," Philos. Mag. A, vol. 67, no. 6, pp. 1405-1421, 1993.

[5] L. M. Tavares and R. P. King, "Single-particle fracture under impact loading," Int. J. Miner. Process., vol. 54, pp. 1-28, 1998. 
[6] E. W. Andrews and K.-S. Kim, "Threshold conditions for dynamic fragmentation of glass particles," Mech. Mater., vol. 31, pp. 689-703, 1999.

[7] A. D. Salman and D. A. Gorham, "The fracture of glass spheres," Powder Technol., vol. 107, pp. 179-185, 2000.

[8] K. Schonert, "Breakage of spheres and circular disks," Powder Technol., vol. 143-144, pp. 2-18, 2004.

[9] A. D. Salman, G. K. Reynolds, J. S. Fu, Y. S. Cheong, C. A. Biggs, M. J. Adams, D. A. Gorham, J. Lukenics, and M. J. Hounslow, "Descriptive classification of the impact failure modes of spherical particles," Powder Technol., vol. 143-144, pp. 19-30, 2004.

[10] L. Vogel and W. Peukert, "Breakage behavior of different materials - construction of a mastercurve for the breakage probability," Powder Technol., vol. 129, pp. 101-110, 2003.

[11] M. Meier, E. John, D. Wieckhusen, W. Wirth, and W. Peukert, "Characterization of the grinding behavior in a single particle impact device: Studies on pharmaceutical powders," Eur. J. Pharm. Sci., vol. 34, pp. 45-55, 2008.

[12] M. Meier, E. John, D. Wieckhusen, W. Wirth, and W. Peukert, "Influence of mechanical properties on impact fracture: Prediction of the milling behavior of pharmaceutical powders by nanoindentation," Powder Technol., vol. 188, pp. 301-313, 2009.

[13] K. T. Chau, X. X. Wei, R. H. C. Wong, and T. X. Yu, "Fragmentation of brittle spheres under static and dynamic compressions: Experiments and Analyses," Mech. Mater., vol. 32, pp. 543-554, 2000.

[14] S. Z. Wu and K. T. Chau, "Dynamic response of an elastic sphere under diametral impacts," Mech. Mater., vol. 38, pp. 1039-1060, 2006.

[15] N. D. Parab, B. Claus, M. C. Hudspeth, J. T. Black, A. Mondal, J. Sun, K. Fezza, X. Xiao, S. N. Luo, and W. W. Chen, "Experimental assessment of fracture of individual sand particles at different loading rates," Int. J. Impact Eng., vol. 68, pp. 8-14, 2014.

[16] W. W. Chen, M. C. Hudspeth, B. Claus, N. D. Parab, J. T. Black, K. Fezza, and S. N. Luo, "In situ damage assessment using synchrotron X-rays in materials loaded by a Hopkinson bar,” Philos. Trans. R. Soc. A, vol. 372, no. 2015, p. $20130191,2014$.

[17] M. Ghadiri and Z. Zhang, "Impact attrition of particulate solids. Part 1: A theoretical model of chipping," Chem. Eng. Sci., vol. 57, pp. 3671-3682, 2002.

[18] Z. Zhang and M. Ghadiri, "Impact attrition of particulate solids. Part 2: Experimental work," Chem. Eng. Sci., vol. 57, pp. 3671-3686, 2002. 
[19] M. B. Zbib and D. F. Bahr, "Fracture behavior of granular polycrystalline silicon using micro-scale and macro-scale indentation techniques," Metall. Mater. Trans., vol. 1E, pp. 20-26, 2014.

[20] D. Rosner, “The long struggle to protect workers' lungs against silicosis," The milbank Quarterly, pp. 191-194, 2014.

[21] M. C. S. de Castro, A. S. Ferreira, K. L. Irion, B. Hochhegger, A. J. Lopes, G. C. Velarde, G. Zanetti, and E. Marchiori, "CT quantification of large opacities and emphysema in silicosis: Correlations among clinical, functional and radiological parameters," Lung, vol. 192, pp. 543-551, 2014.

[22] W. C. Oliver and G. M. J. Pharr, "An improved technique for determining hardness and elastic modulus using load and displacement sensing indentation experiments," J. Mater. Res., vol. 7, pp. 1564-1583, 1992.

[23] D.J. Morris and R.F. Cook, Radial fracture during indentation by acute probes 1: description by an indentation wedging model, Int. J. Fract. 136 (2005) 237-264.

[24] M. Hudspeth, B. Claus, S. Dubelman, J. Black, A. Mondal, N. Parab, C. Funnell, F. Hai, M. L. Qi, S. N. Luo, and W. Chen, "High speed synchrotron x-ray phase contrast imaging of dynamic material response to split Hopkinson bar loading," Rev. Sci. Instrum., vol. 84, pp. 025102:1-025102:7, 2013.

[25] H. Kolsky, "An investigation of the mechanical properties of materials at very high rates of loading," Proc. Phys. Soc. B, vol. 62, p. 676, 1949.

[26] W. W. Chen and B. Song, Split hopkinson (Kolsky) bar: Design, testing and applications. New York: Springer, 2011.

[27] W. S. Rasband, "ImageJ.” U.S. National Institutes of Health, Bathesda, Maryland, USA.

[28] K. L. Johnson, Contact Mechanics. New York: Cambridge University Press, 1985, pp. 90-94. 


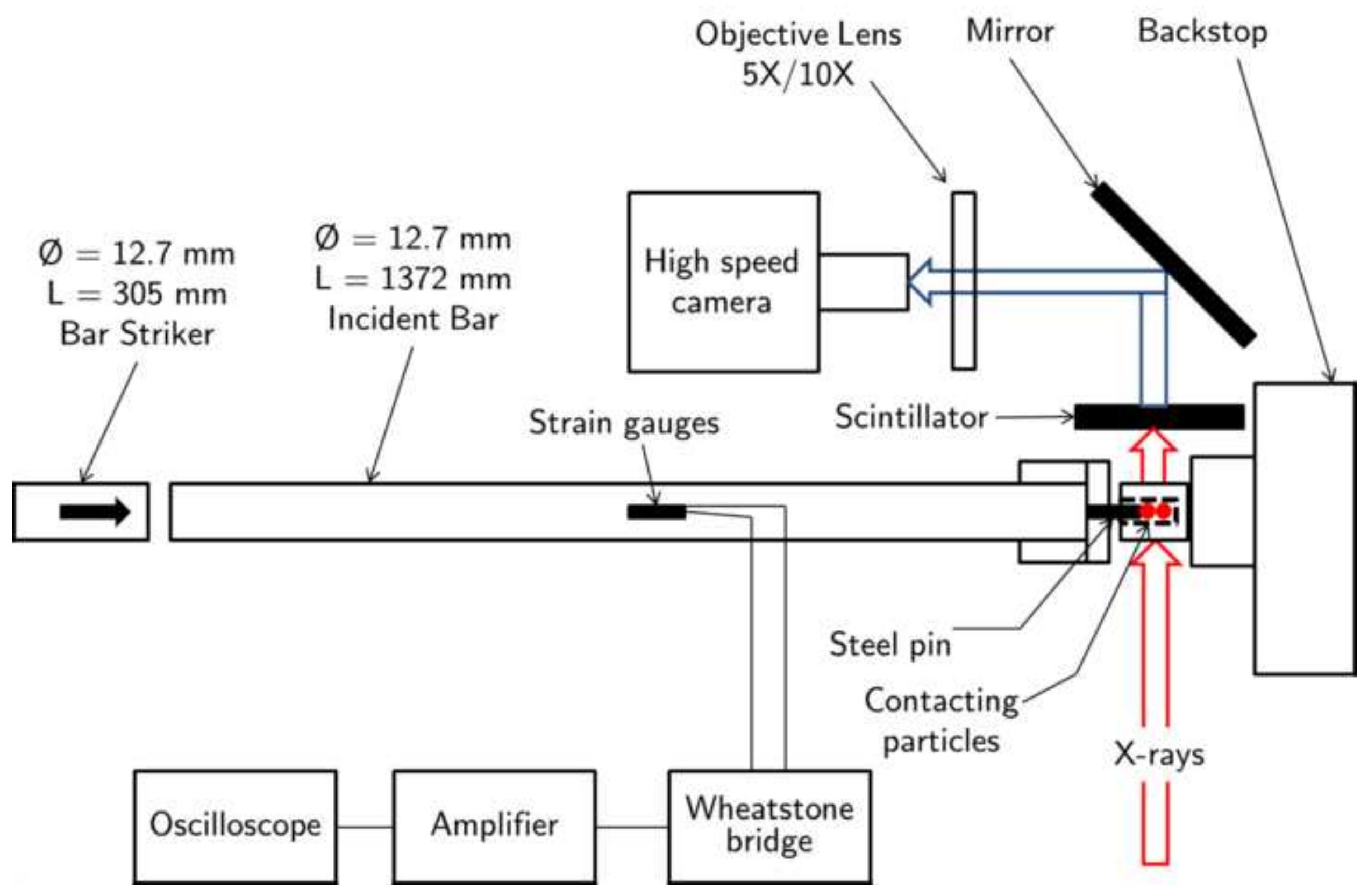


(A)

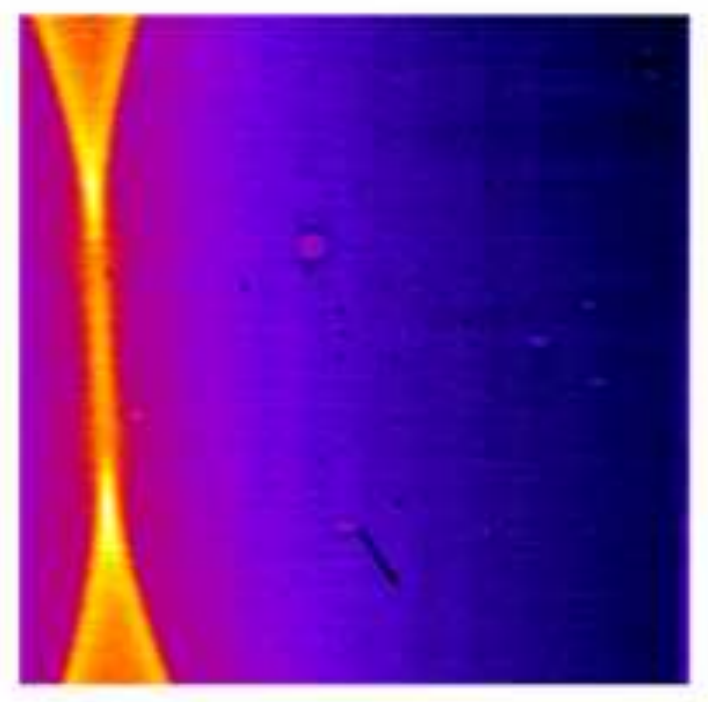

$t=0$

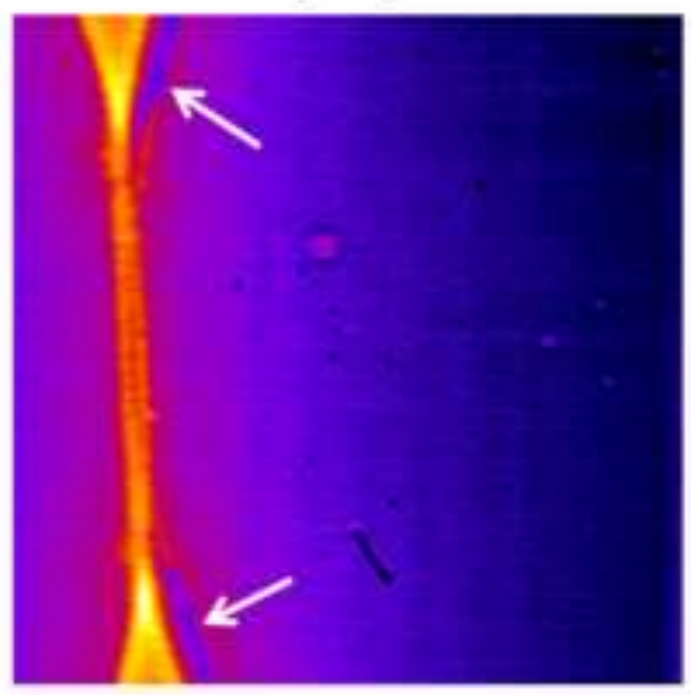

$t=22.1 \mu \mathrm{s}$

(B)

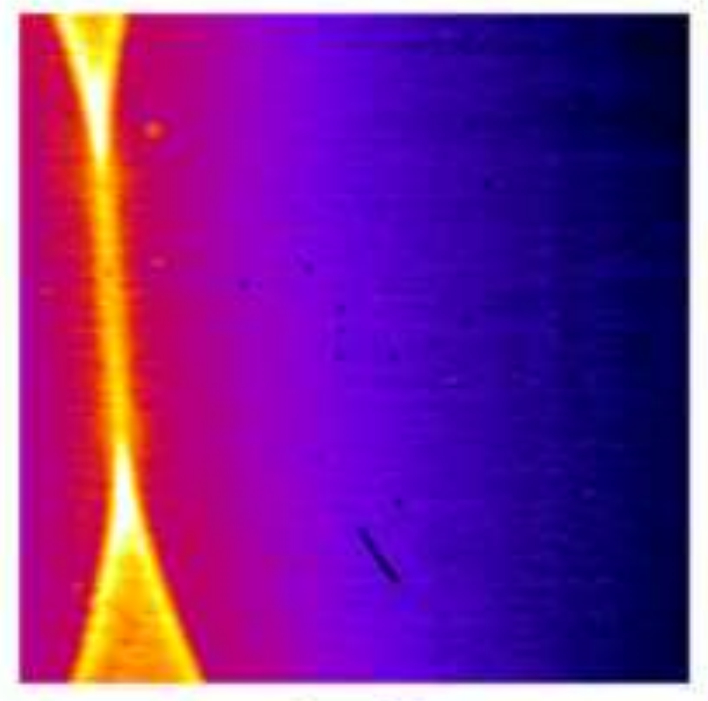

$t=0$

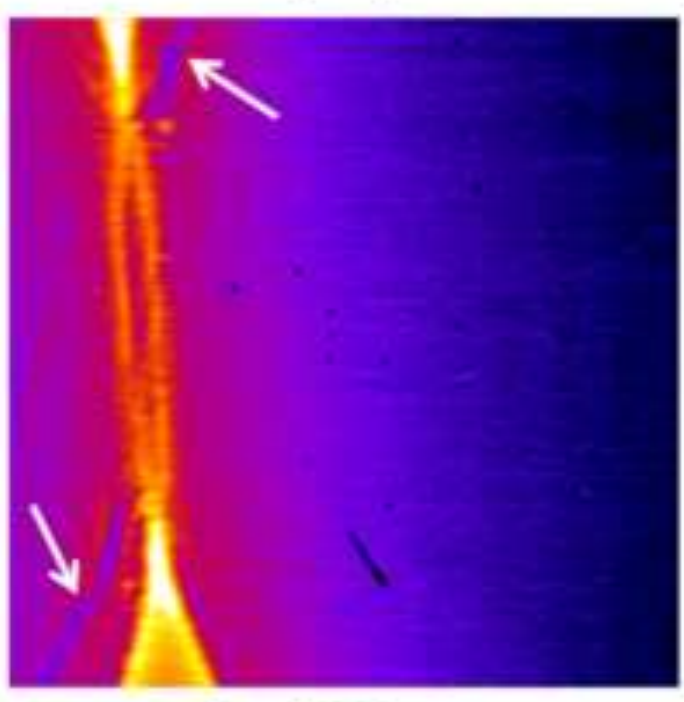

$t=22.1 \mu \mathrm{s}$

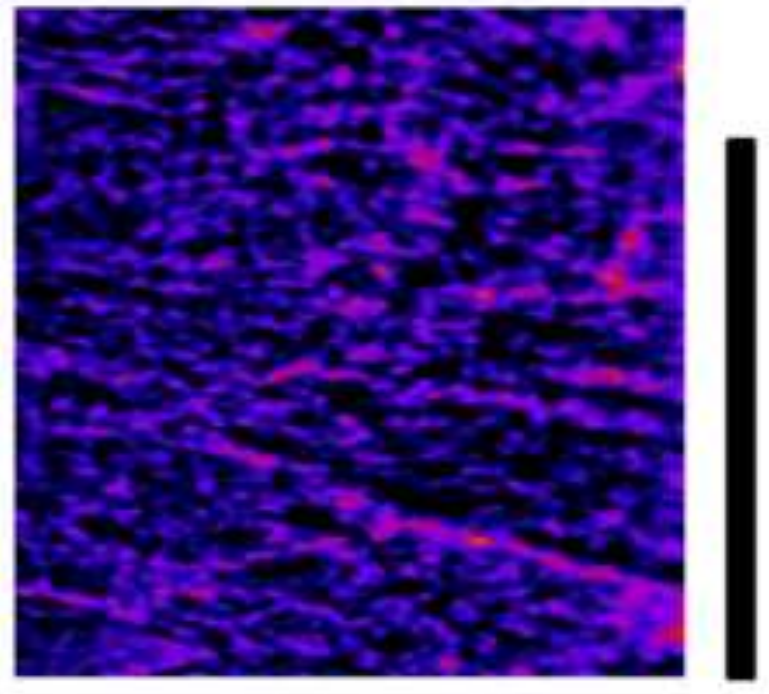

$t=66.3 \mu \mathrm{s}$

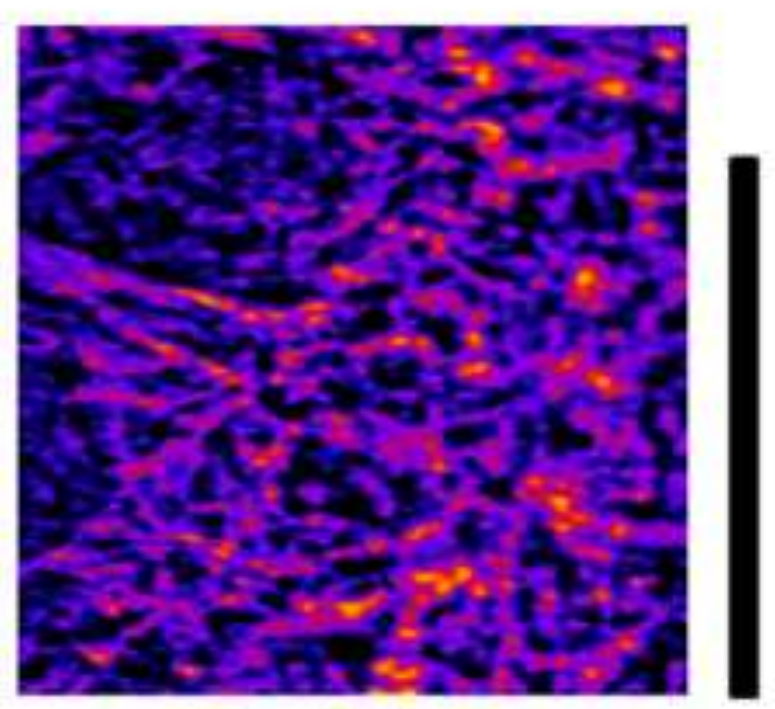

$t=66.3 \mu \mathrm{s}$

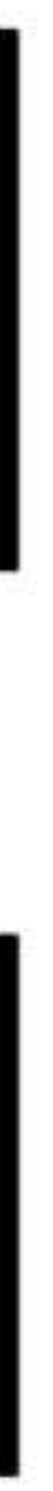

$$
\text { us }
$$




\section{(A)}

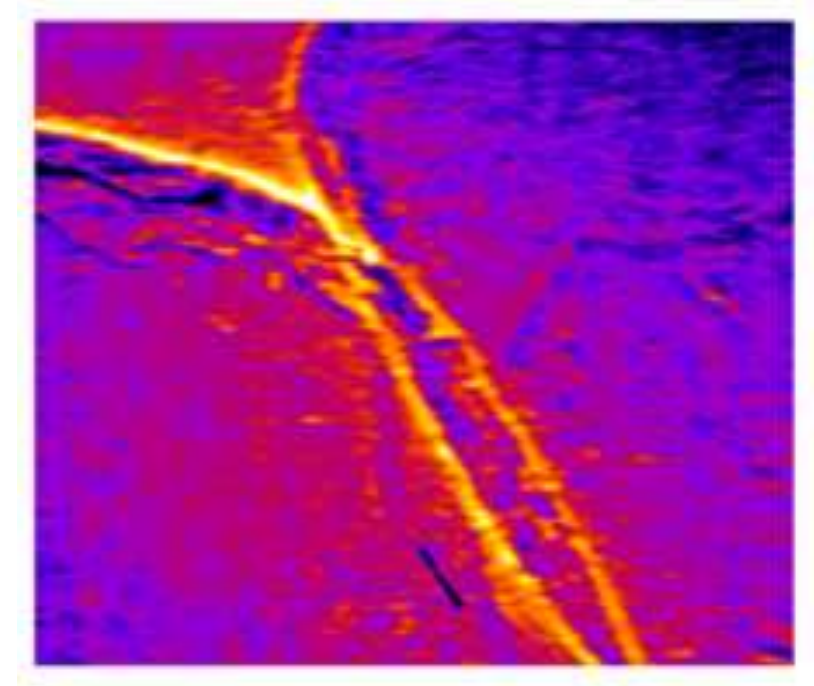

$$
t=0
$$

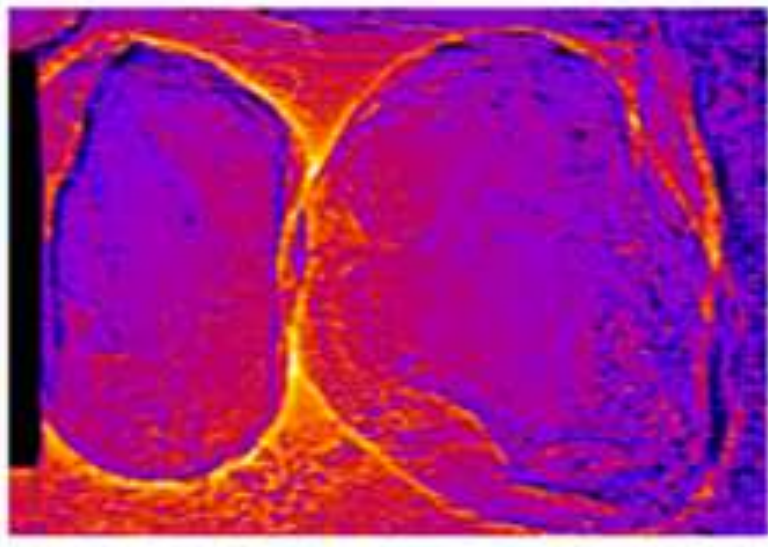

$$
t=0
$$

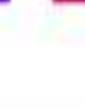

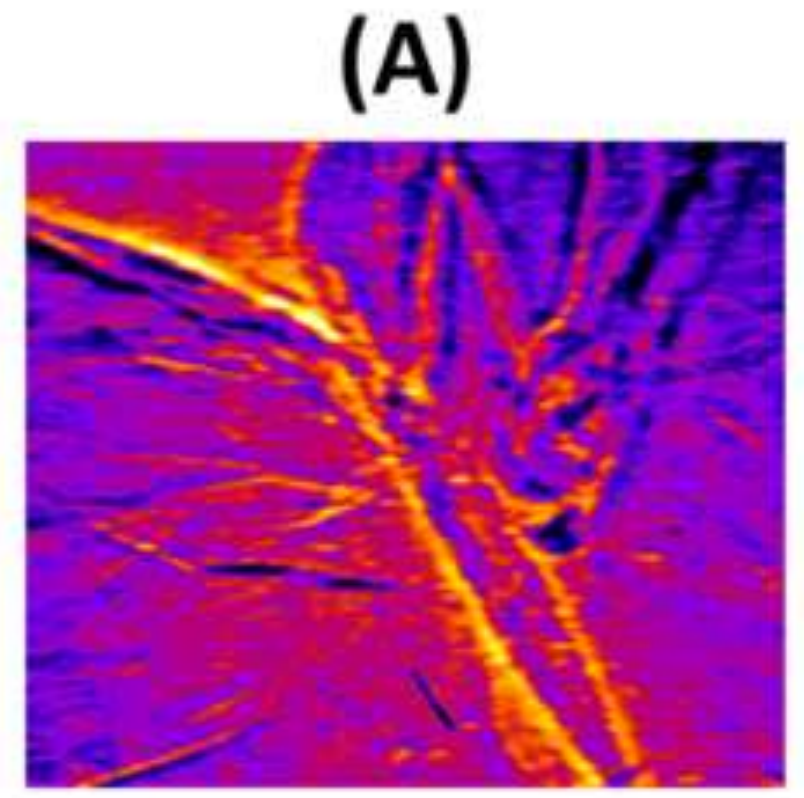

$t=37 \mu \mathrm{s}$

(B)

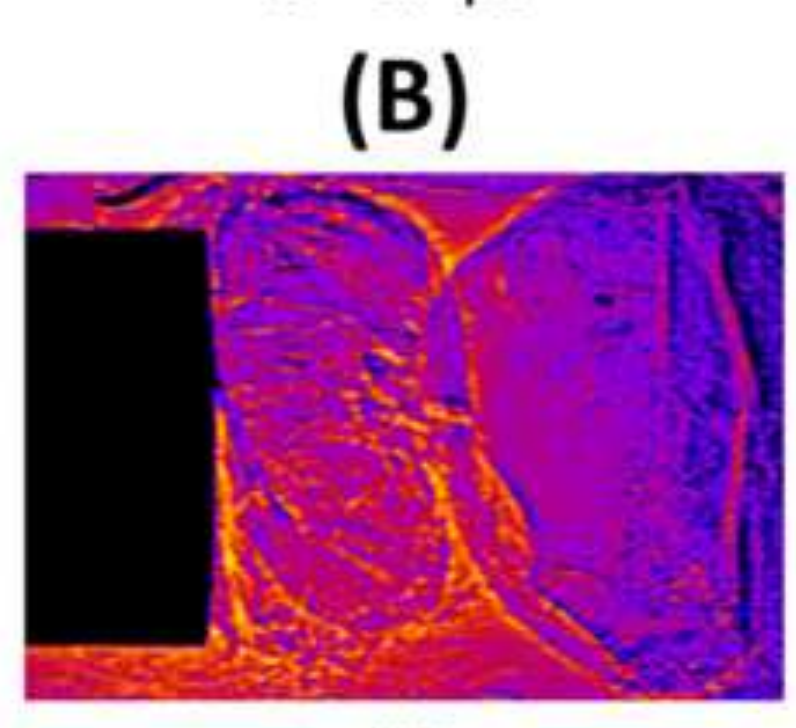

$t=37 \mu \mathrm{s}$

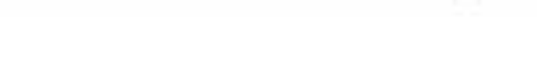

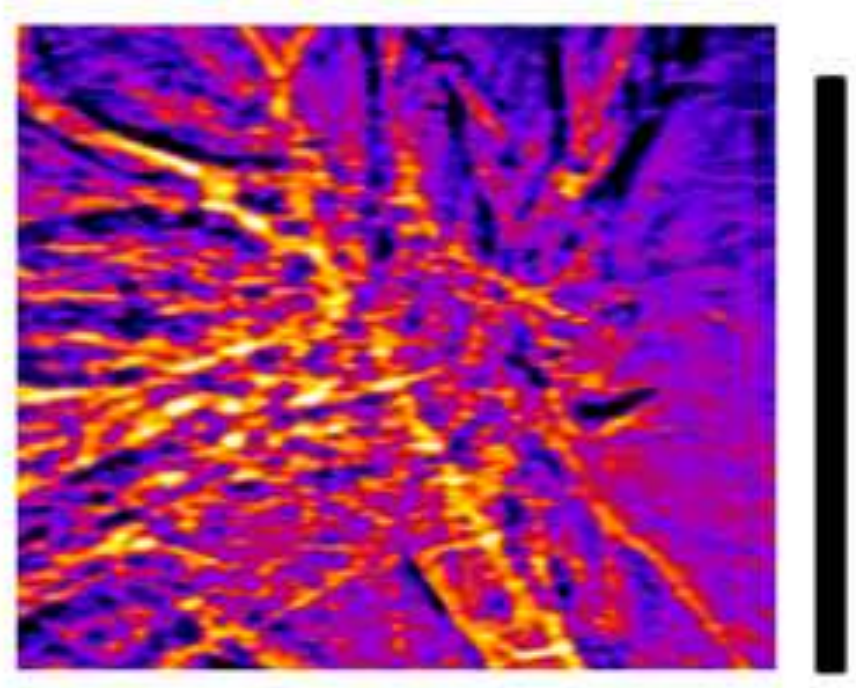

$$
t=74 \mu \mathrm{s}
$$

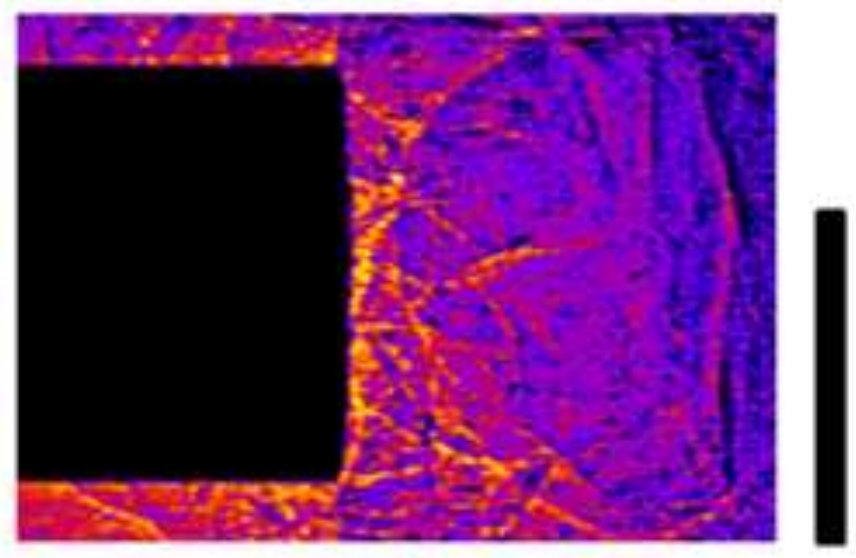

$$
t=74 \mu \mathrm{s}
$$


(A)

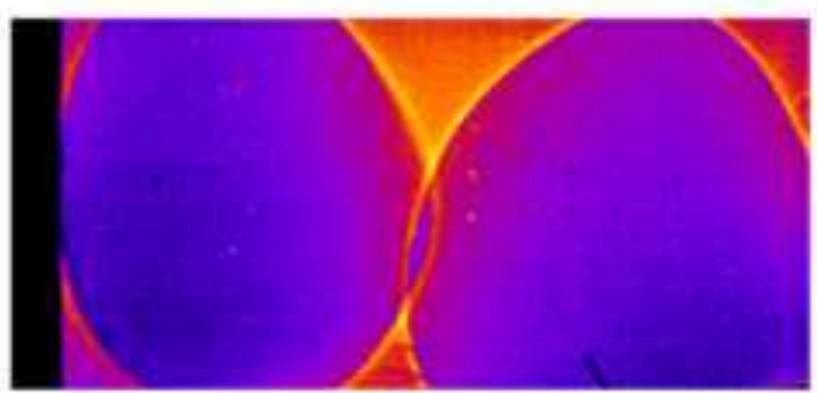

$t=0$

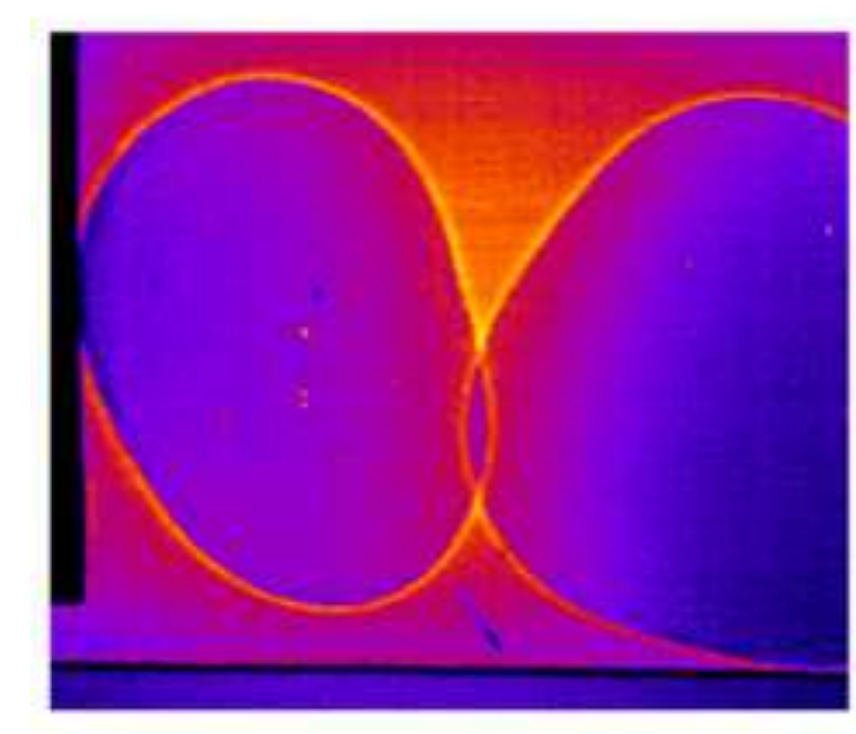

$t=0$

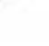

$t=18.5 \mu \mathrm{s}$

(B)
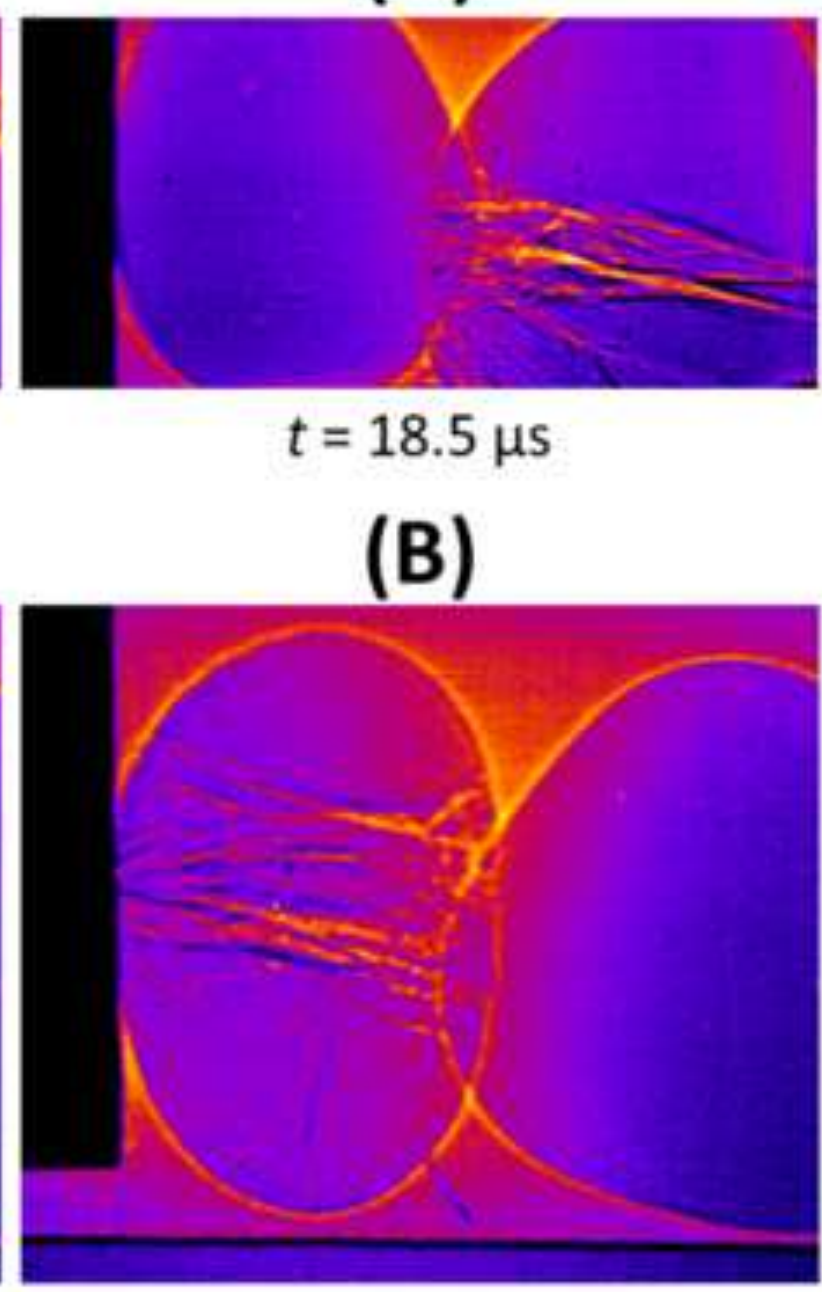

$t=18.4 \mu \mathrm{s}$

$t=18.4 \mu \mathrm{s}$

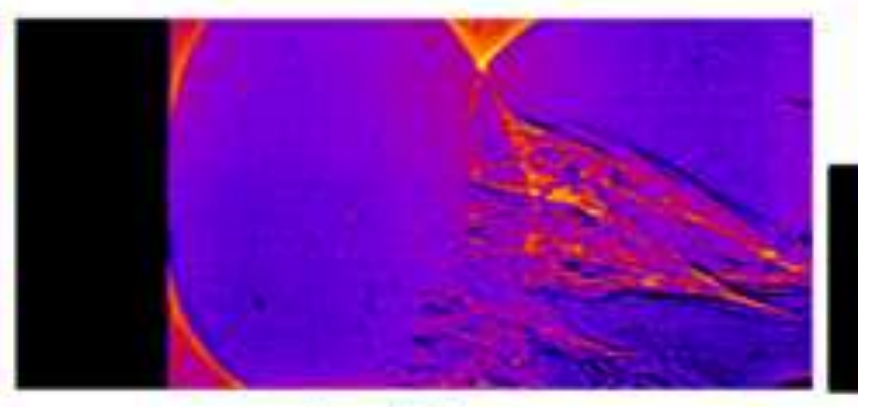

$t=37 \mu \mathrm{s}$

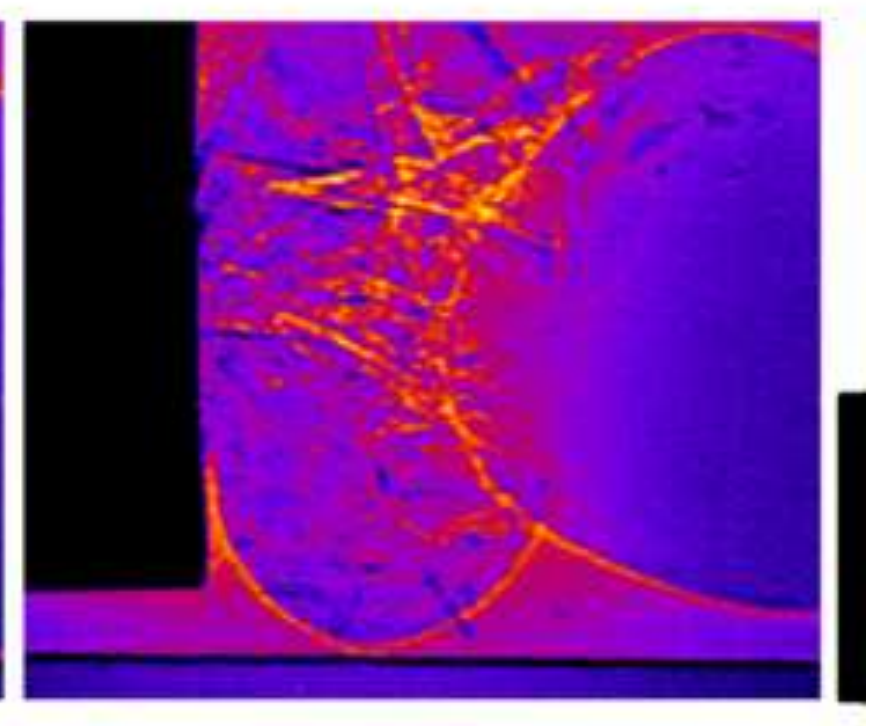

$t=36.8 \mu \mathrm{s}$

us 
(A)

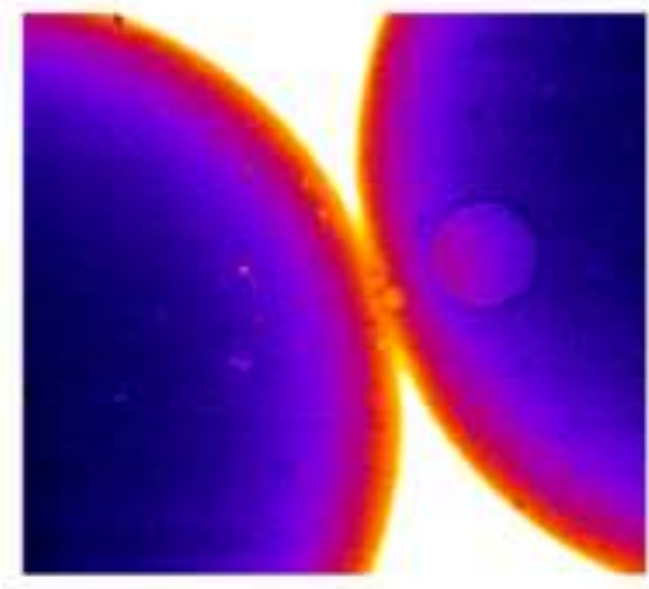

$t=0$

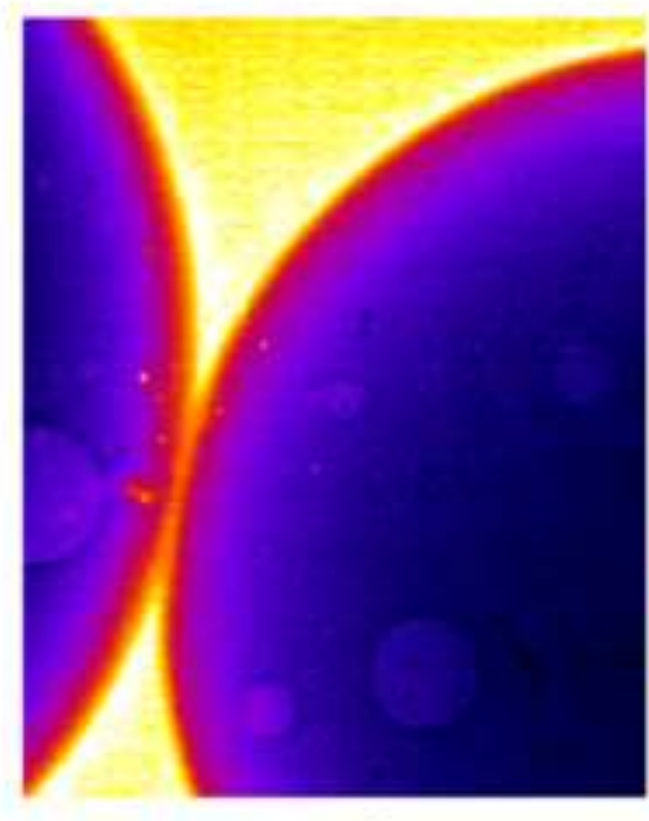

$t=0$ $t=20 \mu \mathrm{s}$

(B)
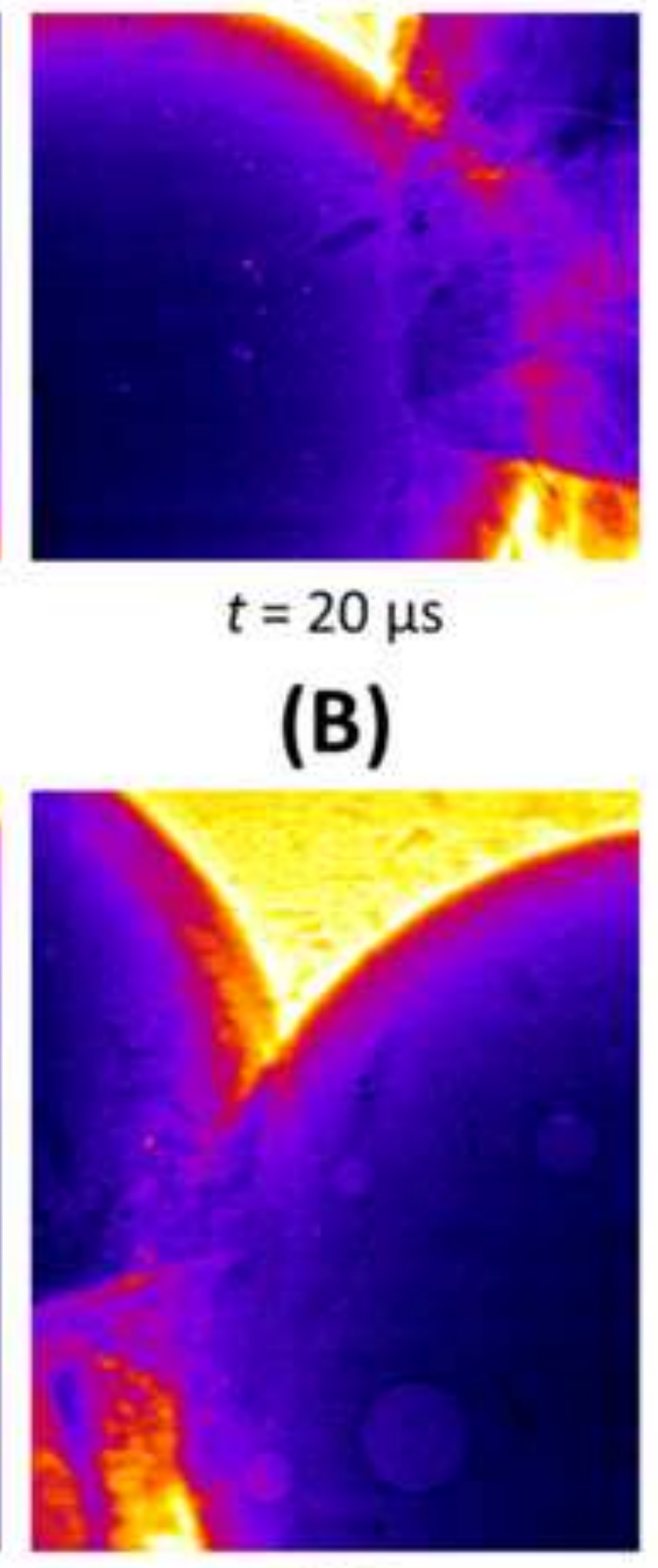

$t=18.5 \mu \mathrm{s}$

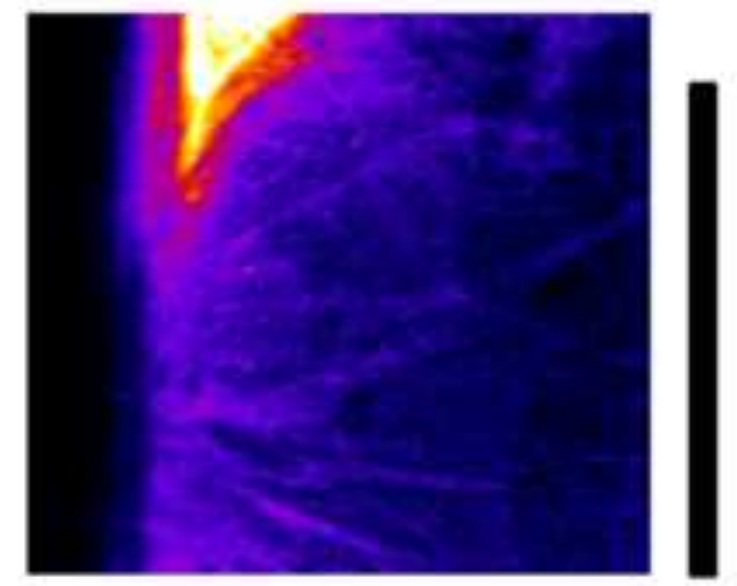

$t=100 \mu \mathrm{s}$

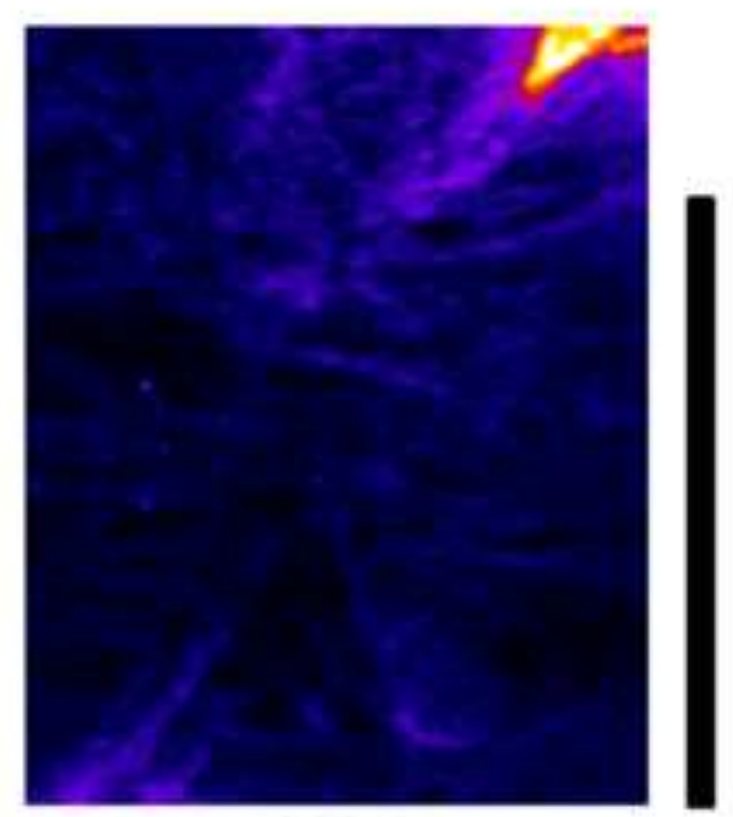

$t=92.5 \mu \mathrm{s}$ 
(A)

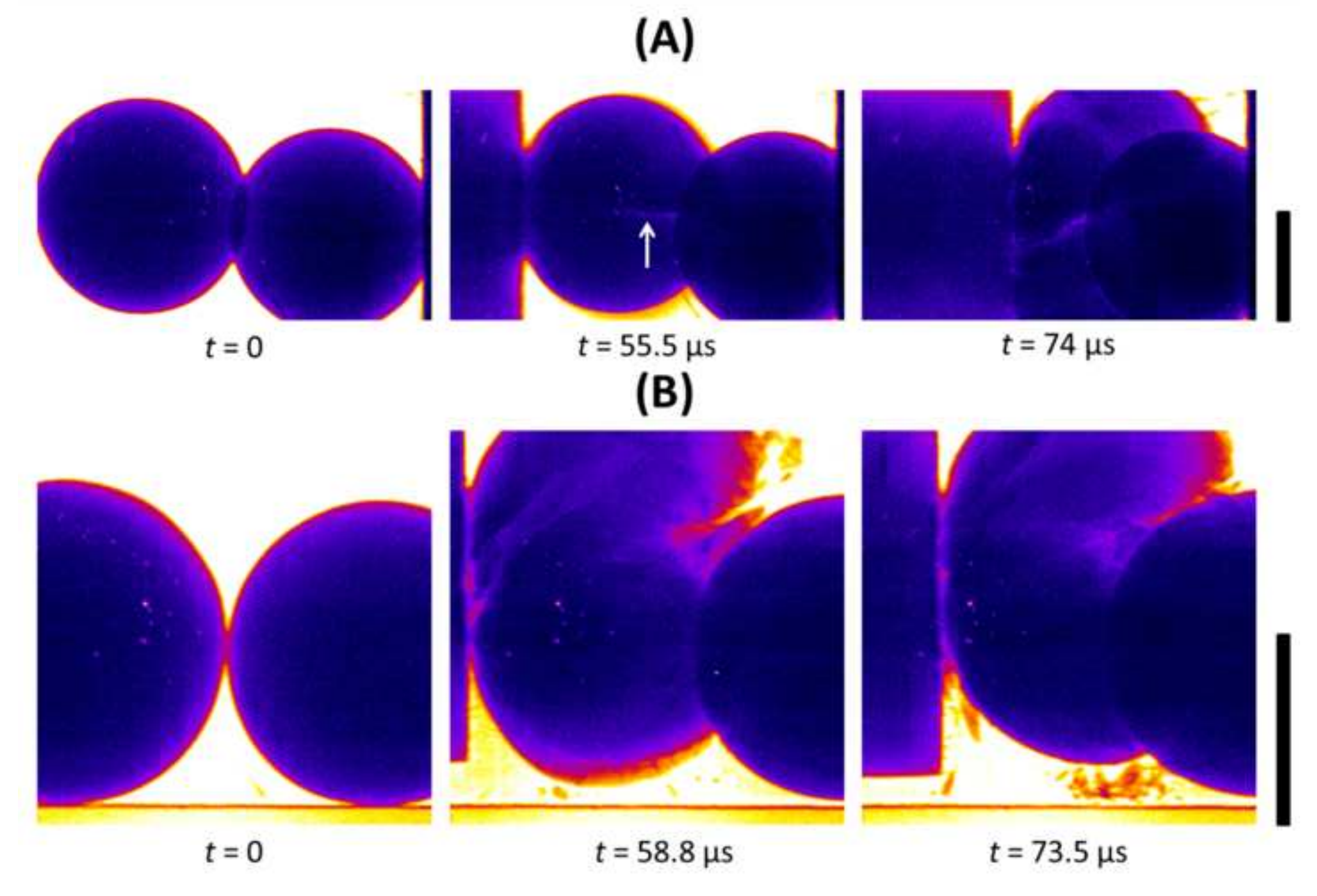
(B)
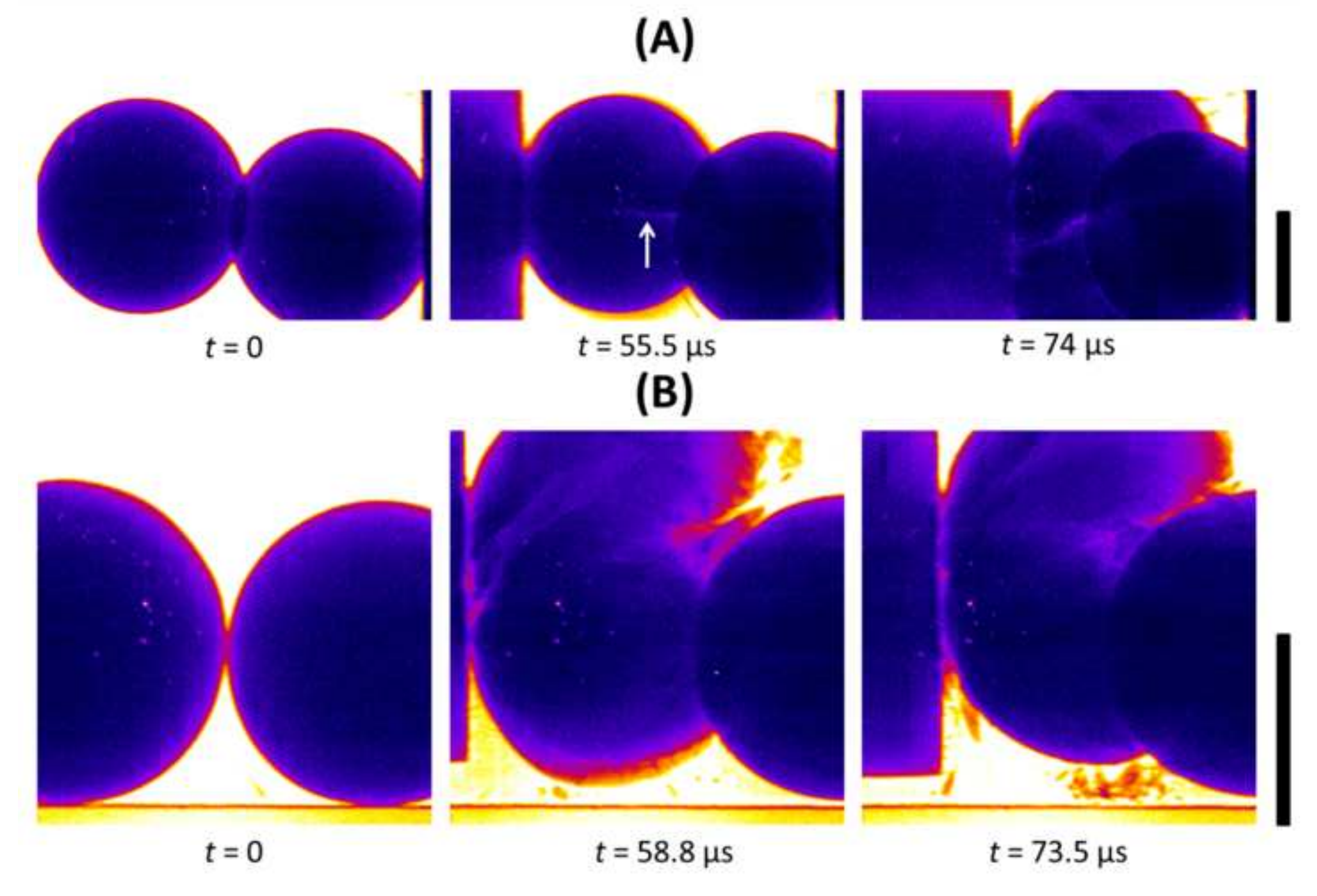
(A)

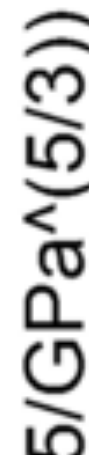

¿ 0.003

है

Q

㐫 0.002

त(

진

은 0.001

Nㅡㄴ

(1)

$\frac{2}{3}$

口

0

SLG Silica Silicon BTG YSZ 


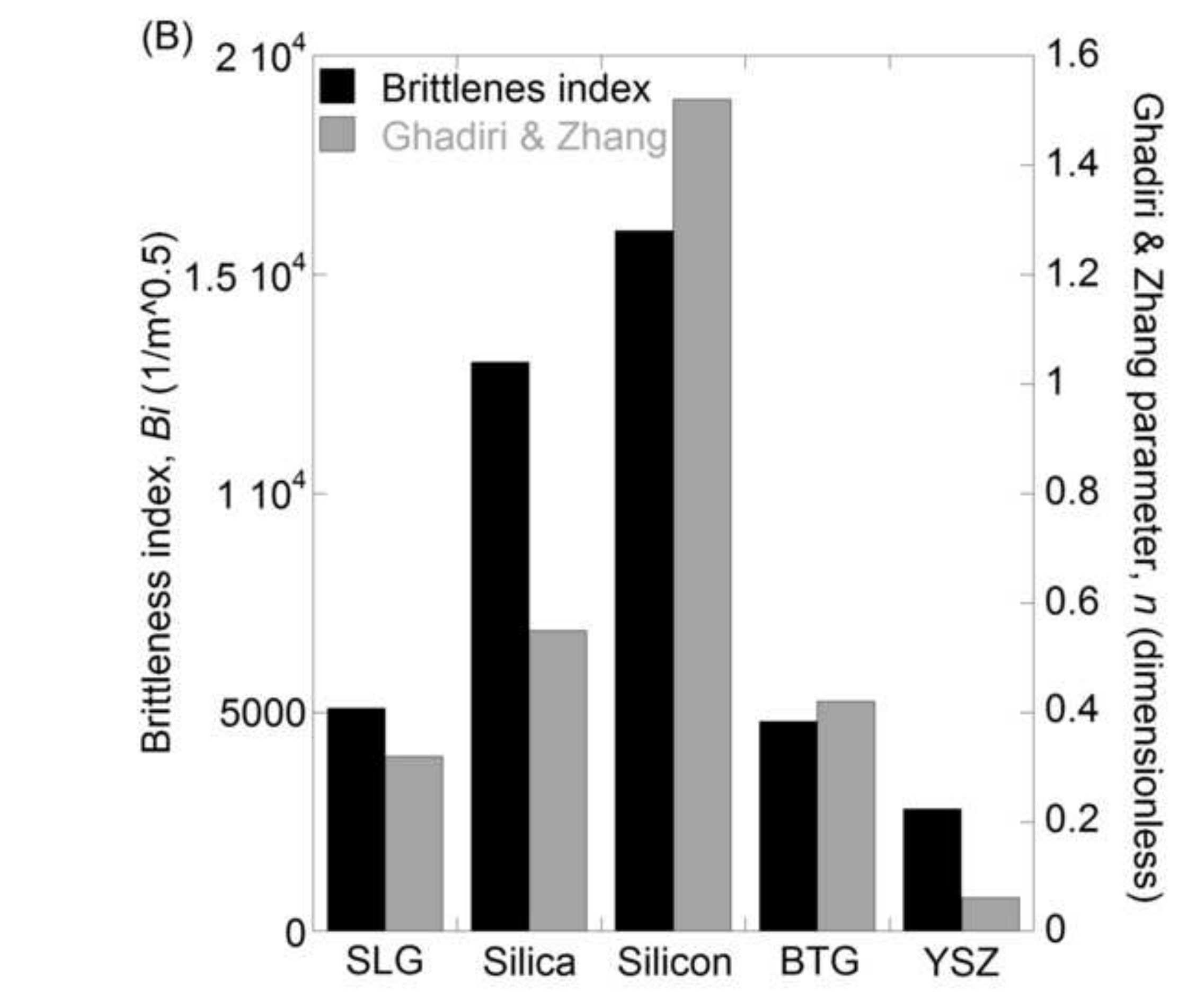

